\title{
Paradoxical brightening of a masked black disc
}

\author{
EDWARD G. HECKENMUELLER AND WILLIAM N. DEMBER \\ UNIVERSITY OF CINCINNATI
}

\begin{abstract}
The paradoxical brightening of a black disc, retroactively masked by a black ring, is documented by data showing disc detection to be an interactive function of interstimulus interval (ISI) and instructions. The brightening effect, which occurs at an ISI of 25 msec., may be implicated in the frequently reported U-shaped masking function.
\end{abstract}

\section{Introduetion}

In a previous article (Heckenmueller \& Dember, 1965) we alluded to a phenomenon that appeared during pilot testing of a forced-choice indicator of backward masking. We were working with a variant of the black disc and ring pattern devised by Werner (1935). Whereas Werner, and others subsequently, relied on Ss' phenomenal reports, we wanted to develop a forced-choice indicator, in the tradition of Blackwell (1953).

For that purpose, the original Werner figures were modified such that in place of a single disc followed and surrounded by a single ring, a second ring was added, adjacent to the first. The disc could appear within either ring, and $\mathrm{S}$ revealed disc detection by correctly indicating its location.

Now, we believed to have found in pilot work a phenomenon noted earlier by Werner (1935, p. 41): under a particular combination of conditions (specifically disc duration $=5 \mathrm{msec}$., ISI $=25 \mathrm{msec}$., disc and ring are black, fixation, disc, ISI, and ring field luminances are all $25 \mathrm{ft}$ lamberts) the disc did not simply disappear, but the interior of the ring containing the disc seemed brighter or livelier than the interior of the empty ring.

It was the purpose of the present study to document that informal observation through testing a prediction derived from the following argument. Ss trying to locate a black disc will avoid selecting the bright-appearing alternative generated under the conditions described above. For those Ss, disc detection, as measured by "percent correct target location," will be depressed. However, it should be possible to so instruct Ss that they will not be "misled" by the brightening effect; this might be accomplished by telling these Ss to select that ring-interior which looks the more different from its background.

Since in our pilot work the brightening effect seemed most pronounced at an ISI of 25 msec., we made the following prediction: disc detection will be an interactive function of ISI and type of instructions. Specifically, Ss given the standard 'black disc"' instructions should not differ from Ss given the "different from background" instructions when ISI is 0 or $50 \mathrm{msec.,}$ but should do less well when ISI is $25 \mathrm{msec}$.

Method

The Ss were 50 students, male and female, from an Introductory Psychology class; they were entirely naive as to the purpose of the experiment.

A 3-field Dodge-type tachistoscope (Scientific Prototype, Model GX) was used. The luminance of each field (25 ft lamberts) was calibrated with a Sprectra Brightness Spot Meter, Model SB. Temporal values were electronically calibrated and were found accurate within $1 \%$ of the range setting.

The three viewing fields were prepared from pen and ink drawings on white cards. For the fixation field, which also served as the ISI field, four small black dots were located $60 \mathrm{~mm}$ apart on both the vertical and horizontal center lines. Disc diameter was 24' of arc, inside diameter of ring, $24^{\prime}$ and outside diameter, $44^{\prime}$ of arc. The space occupied by the two rings subtended $1^{\circ} 44^{\prime}$ of arc, thus maintaining the stimuli within the fovea. Viewing was binocular.

The fixation field was continuously illuminated, except during disc and ring presentations. The $S$ initiated each trial, on signal from $\mathrm{E}$, by pressing a button. A trial consisted of the following sequences: fixation field off; disc on for 5 msec.; ISI field on (for either 0 , 25, or $50 \mathrm{msec}$., randomly determined); rings on for $100 \mathrm{msec}$; fixation field on. Immediately after each trial, the $\mathrm{S}$ indicated disc location by saying "left" or "right," guessing when necessary. Each S had 48 trials at each of the 3 values of ISI.

Half the Ss were randomly assigned to the group given instructions to "locate the black disc." The other 25 Ss were told to "look for a difference between the interior of the rings and the background surrounding the rings; tell me which ring interior looks different from the background."

\section{Results}

The Ss' overall performance, as a group, was only slightly better than chance, due most likely to the Ss' naivete and to the difficulty of their task. Despite this, it was possible to analyse the data for the predicted interaction between the ISI and instructions. For the statistical analysis, the values of percent correct disc location were corrected for guessing and then subjected to the ara $\sin$ transformation.

At both the 0 and 50 ISI values, $t$-tests revealed no difference between the two instruction conditions; however, at the ISI value of $25 \mathrm{msec}$., the performance 


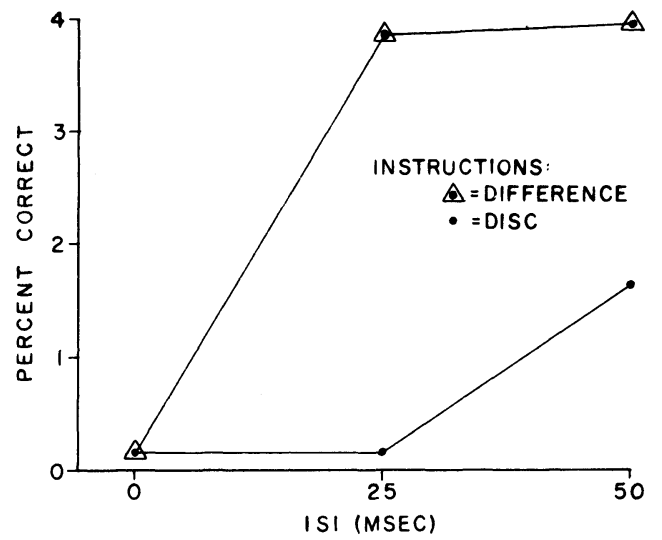

Fig. 1. Mean percent correct disc location, corrected for guessing, as a function of interstimulus interval (ISI) and instructions. Each point is based on 1200 observations.

of the two instruction groups was significantly different $(t=1.405 ; d f=48 ; p<.10)$. A graphical presentation of the results is given in Fig. 1 .

\section{Diseussion}

The results support the hypothesis of an interaction between ISI and instructions and seem to constitute evidence for the existence of a paradoxical brightening effect. While the effect is interesting in its own right, and deserves further investigation, we would like to focus here on one of its implications.

A major impediment to an adequate theory of backward masking lies in the rather frequent reports of a nonmonotonic relation between ISI and extent of masking. Under certain conditions still not fully delimited, extent of masking increases as ISI increases from 0 , reaches a maximum, and then declines. This type of relation prevailed in Werner's own research, and has since been reported in masking studies using Werner-type figures (e.g., Kolers, 1962) as well as stimuli very different from Werner's, such as letters (e.g., Averbach \& Coriell, 1961; Weisstein \& Haber, 1965).

Now, with respect to those studies using Werner-type figures, the paradoxical brightening effect may play some role in generating the nonmonotonic function. If, at some value of ISI greater than 0 , the masked black disc looks bright, Ss giving phenomenal reports may be reluctant to say that they saw the disc; Ss in a forcedchoice situation, such as ours, may tend to choose the wrong alternative. In either case, disc detection would be spuriously low at that value of ISI where the paradoxical brightening effect takes place.

At this point we can see no comparable role for the brightening effect in those experiments using letters as stimuli. However, it is also not entirely clear that letter-masking and disc-masking involve identical mechanisms.

\section{References}

Averbach, E., \& Coriell, A. S. Short-term memory in vision. Bell Sys. tech. J., 1961, 40, 309-328.

Blackwell, H. R. Psychophysical thresholds: experimental studies of methods of measurement. Ann Arbor: University of Michigan Press. (Eng. Res. Bull. No. 36), 1953.

Heckenmueller, E. G., \& Dember, W. N. A forced-choice indicator for use with Werner's disc-ring pattern in studies of backward masking. Psychon. Sci., 1965, 3, 167-168.

Kolers, P. A. Intensity and contour effects in visual masking. Vis. Res., 1962, 2, 277-294.

Weisstein, Naomi \& Haber, R. N. A u-shaped backward masking function in vision. Psychon. Sci., 1965, 2, 75-76.

Werner, H. Studies in contour: I. Qualitative analyses. Amer. J. Psychol., 1935, 47, 40-64. 